\title{
The Electrical and Mechanical Properties of Porous Anodic 6061-T6 Aluminum Alloy Oxide Film
}

\author{
Tsung-Chieh Cheng and Chu-Chiang Chou \\ Department of Mechanical Engineering, National Kaohsiung University of Applied Science, Kaohsiung 807, Taiwan \\ Correspondence should be addressed to Tsung-Chieh Cheng; tcchengme@cc.kuas.edu.tw
}

Received 30 September 2014; Accepted 23 March 2015

Academic Editor: Shafiul Chowdhury

Copyright ( 2015 T.-C. Cheng and C.-C. Chou. This is an open access article distributed under the Creative Commons Attribution License, which permits unrestricted use, distribution, and reproduction in any medium, provided the original work is properly cited.

\begin{abstract}
The properties of the growth of the 6061-T6 aluminum alloy oxide were studied using sulfuric acid anodization. The parameters for the manufacturing process include electrolyte categories, electrolyte concentration, and operating voltages. The results showed that the aluminum oxides obtained by anodization process are mainly amorphous structure and the anodic current density is an important factor affecting the rate of response for oxygen and aluminum ions in barrier. In this experiment, polish process is very important to stable the anodic aluminum oxide film and then it will get the better properties of anodic film. Besides, when using sulfuric acid as the electrolyte, the increase of anodic voltage also increases the rate of reaction which increases the mechanical and electrical properties of anodic oxide film, but too large applied anodic voltage will reduce the mechanical and electrical properties of film because of the crack of the anodic oxide film.
\end{abstract}

\section{Introduction}

Aluminum is one of the most consumed metals and it is the third most abundant element in the earth's crust ranking behind oxygen and silicon. Since aluminum is light weight with high specific strength, its alloy materials own outstanding properties in many aspects such as corrosive resistance, thermal conductivity, machinability, and surface treatment [1]. It is highly ductile and does not fracture even at $-193^{\circ} \mathrm{C}$ so it can be rolled to thin plates or films, pulled to thin strings, or protruded into different kinds of shapes. Since the end of the twentieth century, aluminum materials have been massively used and moved into a rapid development period. It has been greatly used in aerospace, transportation, and machinery. To date, aluminum alloy and aluminum magnesium alloy have been broadly applied to major industries, daily-life products, transportation vehicles, and even semiconductor industry.

Aluminum is highly active and easily reacts with oxygen to form the oxide layer on the surface of the material in atmosphere environment. The thickness of the native oxide is only few ten to few hundred of angstroms and its structure is loose and not uniform. In recent researches, we can grow a dense and continuous oxide layer on the surface of aluminum by using chemical methods such as chemical treatment, electroplating, and anodizing to protect the aluminum alloy from being eroded or abraded from exterior environment. After Pinner and Sheasby received the patent of using sulfuric acid for anodizing in 2001, this technology has been widely used in industry [2]. Most studies have considered the (micro) hardness or wear resistance of thick porous aluminum anodic films concern oxides formed (typically thicker than $25 \mu \mathrm{m}$ ) under hard anodizing conditions. According to these previous studies [3-6], anodic films of varying morphologies can be produced on $\mathrm{Al}$ if both electrolyte and electrolysis conditions are carefully selected; for example, certain combinations of electrolyte $\mathrm{pH}$, concentration, anion content, and current density allow formation of either barrier and/or porous oxide films. Scott [7] considered anodizing in a sulfuric acid electrolyte with varying the electrolyte temperature in the range from $-5^{\circ} \mathrm{C}$ up to $15^{\circ} \mathrm{C}$ at a constant applied current density of $4 \mathrm{~A} / \mathrm{dm}^{2}$. The results indicated that the electrolyte temperature hardly influences the abrasion resistance of the resulting AAF. Koizumi et al. [8] dealt with anodizing at current densities from 1 to $8 \mathrm{~A} / \mathrm{dm}^{2}$ in a mixed sulfuric acid-oxalic acid electrolyte at a temperature range from $5^{\circ} \mathrm{C}$ to $20^{\circ} \mathrm{C}$. They 
found that increasing electrolyte temperature will decrease wear resistance of material especially at lower applied current densities. Recently, a highly ordered honeycomb structure was obtained in oxalic acid solution at $40 \mathrm{~V}[9,10]$ and in sulfuric acid at voltages ranging from 20 to $27 \mathrm{~V}$ [11]. It was reported that pore diameter and interpore spacing were linearly proportional to the applied voltage [12]. It was also proposed that self-ordering requires a porosity of $10 \%$ which is independent of the specific anodization conditions and corresponds to aluminum of about 1.2 [13]. Besides, Keller et al. [14] presented a model of anodizing oxide film with hexagonal structure. They imagined the anodized aluminum oxide using scanning electron microscopy (SEM) and observed the surface of the oxide with a regular hexagonal nanopores array. From previous studies, the anodized oxide film shows good hardness and excellent electrical and thermal insulation. Therefore, in the past few decades, many applications such as increasing rigidity of the aluminum alloys to improve the corrosive resistance, abrasive resistance, electrical insulation, and thermal insulation can be applied in capacitor, semiconductor, and aerospace industry [15-18]. In general, the anodic process efficiency is also affected by the nature of the electrolyte, such as (i) concentration, (ii) pH, (iii) presence of activating anions, (iv) agitation conditions, and (v) electrolyte temperature. Oxidation efficiency decreases as a result of local film dissolution and associated formation of a porous layer [19-23].

In the present work, we studied the growth of the 6061T6 aluminum alloy oxide using sulfuric acid anodization. By altering the fabrication parameters, (1) film thickness, (2) surface morphology, (3) hardness, and breakdown voltage for anodic aluminum alloy oxide $(\mathrm{AAO})$ were also investigated in this paper.

\section{Experimental Method}

To distribute the electrical field more uniformly on the surface of anodizing samples, a polishing step was added before anodizing. First, sand papers with grade number from low to high $(600,1200$, to 2000$)$ were used for the coarse polishing. Then, aluminum oxide powder with size of $0.3 \mu \mathrm{m}$ in diameter was used for fine polish. Next, sodium hydroxide, acetone, and nitric acid were then used to clean the samples to remove grease and impurities. Finally, these specimens were soaked in an electrolyte with perchloric acid and ethanol mixed with the ratio of 1 to 4 , and 5 volts of voltage was applied for 5 minutes for the electrochemical polishing procedure. The samples surface is highly smooth after the present polishing process. Next, we prepare sulfuric acid with concentration of $0.1 \mathrm{M}$ and $0.3 \mathrm{M}$. An ice water bath was used to cool down the temperature during the electrolyte mixing process.

The polished specimens were connected to the anode and graphite electrode was used as cathode. Both electrodes were then submerged into the acidic electrolytes and a DC current was applied for anodizing and applied anodic voltage from 25 to $60 \mathrm{~V}$ was used for sulfuric acid bath. After anodizing, the samples were removed from the anodizing bath, cleaned with DI water, and dried by nitrogen gas.

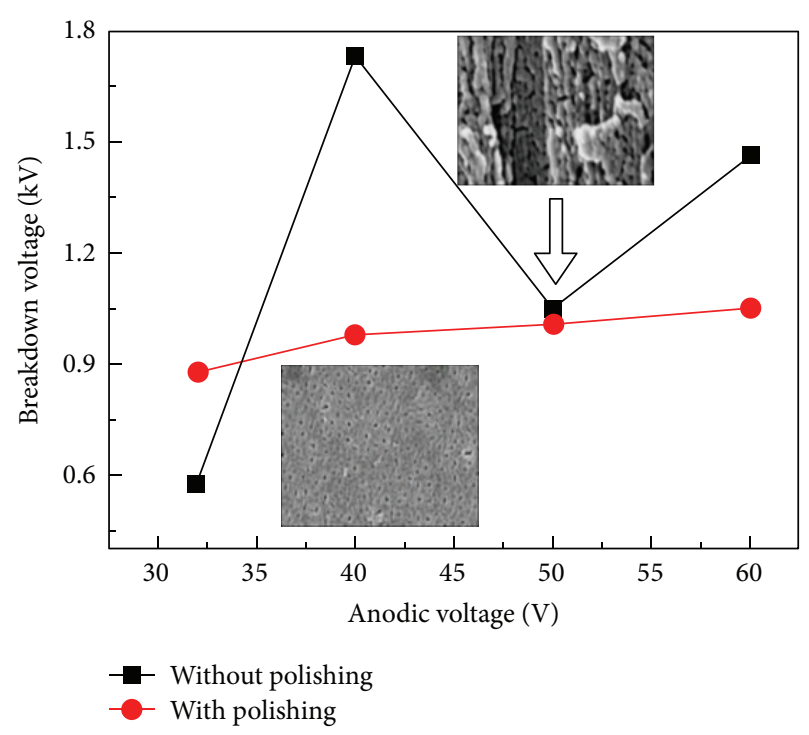

FIGURE 1: Breakdown voltage and anodic voltage for aluminum alloy samples before and after polishing process.

In our experiment, energy dispersive X-ray spectrometry (EDS), X-ray diffractometer (XRD), and scanning electronic microscope (SEM) were used for chemical element analysis, crystal structure evaluation, and surface morphology observation, respectively. Then, hardness and breakdown voltage were tested using micro hardness tester and dielectric withstanding tester. Finally, image was used for porosity calculation.

\section{Results and Discussions}

3.1. Polishing Process. Figure 1 shows the breakdown voltage for anodizing oxide films with and without polishing. The result shows that the surface roughness influences the measurement accuracy. With polishing process, the breakdown voltage increases as anodic voltage increases. However, samples without polishing process did not show the controllable trend. The reason for this irregular trend of samples without polishing process is due to the focusing of the electric field at scratches on the surface of the samples. The large roughness of sample surface will cause the irregular anodic pores of the anodic oxide film. Therefore, anodic pores tend to be generated at these strong local field sites and make the thickness of the barrier and the arrangement of the anodic pores less uniform. In addition, this field also decreases the uniformity of anodic pores alignment in the oxide film. Since the anodizing specimens without polishing process show unpredictable trend for the breakdown voltage, lowering the surface roughness can make both the alignment of anodic pores and the uniformity of anodic oxide film (Figure 1). This polishing process also stabilizes the later measurements and analysis procedures.

3.2. XRD Crystallography Analysis. The crystal structure of the aluminum alloy samples was also analyzed using XRD. 


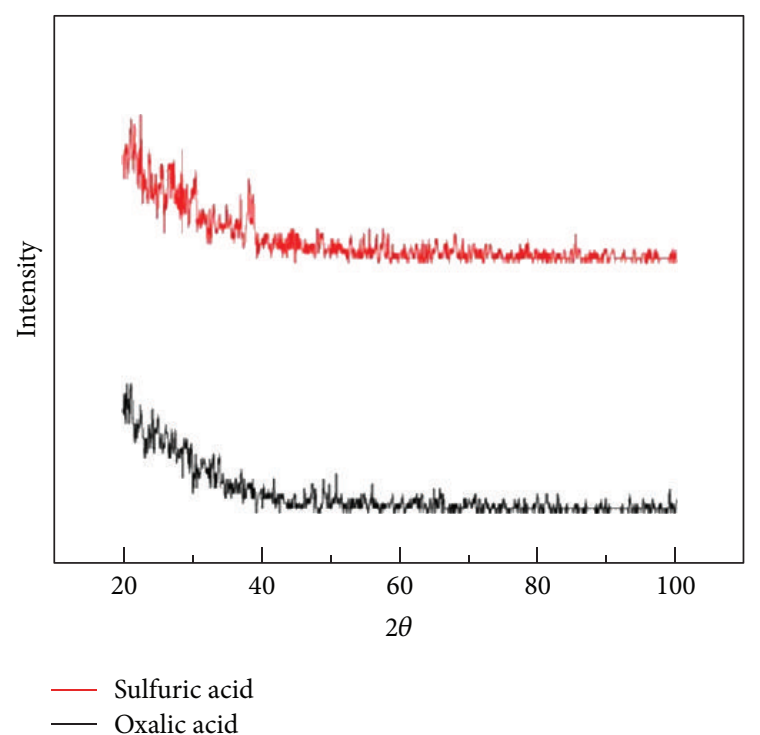

FIGURE 2: A plot showing the results obtained using grazingincidence diffraction X-ray (GID X-ray) (red: sulfuric acid anodizing samples and black: oxalic acid anodizing samples).

To prevent the destruction of the thin film, we used grazingincidence X-ray diffraction (GIXRD). No obvious peak can be seen in Figure 2; therefore, the crystal structure of the present aluminum oxide film is amorphous.

3.3. Oxide Film Thickness and Breakdown Voltage. In our anodizing experiments, DC voltage was used to anodize the aluminum alloy-T6061. Both thickness and breakdown voltage of the grown oxide were measured under different electrolyte concentrations (Figure 3). The results showed that the thickness of oxide increases with anodic voltage. In addition, the higher anodic voltage and electrolyte concentration will make the oxide thickness larger because of the increasing of anodic reaction speed. This oxide thickness increase is mainly due to increasing of electrical current density with increasing of both electrolyte concentration and applied anodic voltage [24]. Increasing of current density increases both the ion exchange rate in the barrier and the growth rate of aluminum anodic oxide. On the other hand, the current density increase also increases the rate of oxide dissolution. If currents keep rising, the dissolution rate will eventually be larger than oxide growth rate and the oxide thickness begins to decrease. As shown in Figure 3, the thickness is close to steady state with increasing the anodic voltage at sulfuric acid concentration of $0.3 \mathrm{M}$. It implies that oxide growth rate is very similar to the dissolution rate. Therefore, an optimal anodic voltage exists for the largest oxide growth rate. As shown in Figure 3, the trend of oxide growth is still increasing with higher anodic voltage; therefore, we know that the growth rate is still larger than dissolution rate in our experiments.

To understand the dielectric properties of the oxide film, a dielectric withstanding tester was used for breakdown voltage measurement. Figure 3 compares the thickness of the oxide films to their breakdown voltages. Overall, breakdown

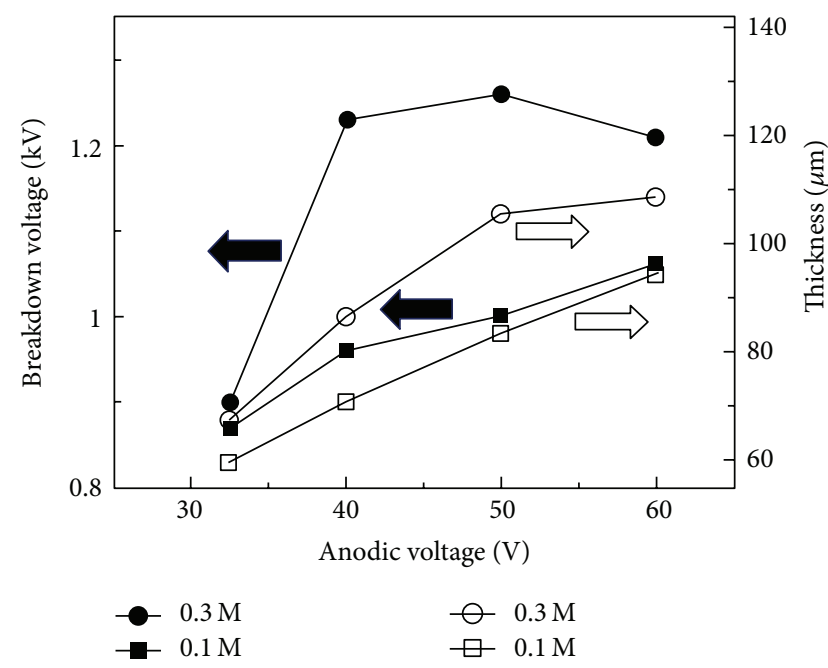

FIGURE 3: Oxide film thickness and breakdown voltage for the 6061-T6 aluminum alloy anodizing process under different anodic voltages and electrolyte concentrations using sulfuric acid.

voltage increases with oxide film thickness. However, for the sulfuric acid bath with higher concentration of $0.3 \mathrm{M}$, breakdown voltage decreases with increasing of oxide thickness when anodic voltage is higher than $50 \mathrm{~V}$. The reason for this breakdown voltage decrease is that the higher oxide growth rate in sulfuric acid bath will induce a massive heat production on top of the barrier and increase both electrolytic corrosion and number of defects [25].

3.4. Porosity and Hardness of Anodic Oxide Films. SEM images show the morphology of the samples after anodizing process using sulfuric acid. As shown in Figure 4, the pores density decreases with increasing of anodic voltage with sulfuric acid anodizing. As discussed by Masuda and Satoh [26], rate of reaction is affected by anodic voltage. For sulfuric acid anodizing, oxide grows faster than other acid samples. When anodic voltage increases, the thickness of the barrier also increases. This voltage increase turns the shape for the bottom of the barrier into hemispheric and then the thickness of barrier increases and also increases the distances between pores. Therefore, as shown in Figure 4, the porosity of aluminum oxide layer decreases with the increase of anodic voltage.

The relationship between porosity and hardness was discussed in this paper as shown in Figure 5. The porosity of aluminum oxide decreases as anodic voltage increases because of the increasing of barrier thickness; therefore, hardness increases with the anodic voltage. This can be explained by Jessensky's theorem [5]. In anodizing process, aluminum reacts with oxygen and turns into aluminum oxide which causes the volume of oxide to expand and induces an internal stress in aluminum/oxide interface. Therefore, this boundary stress increases with the oxide thickness and anodizing voltage. On the other hand, the porosity of aluminum oxide in sulfuric acid anodization decreases as anodic voltage increases. In addition, higher interface stresses will increase the hardness of anodic film with the decrease of porosity and 


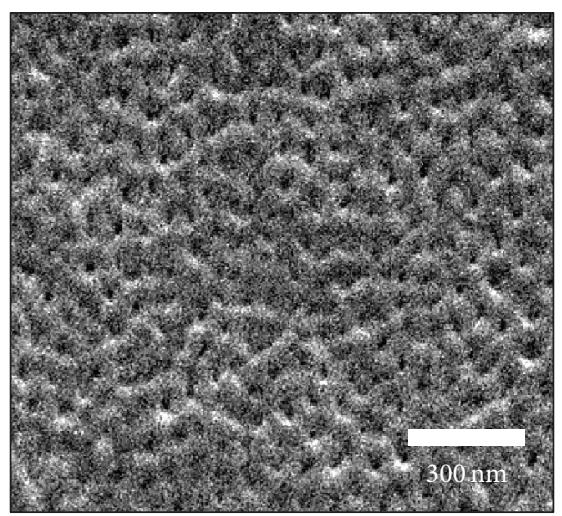

(a)

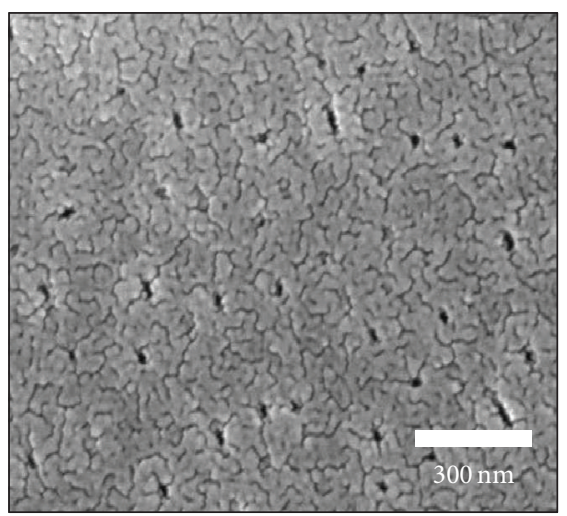

(b)

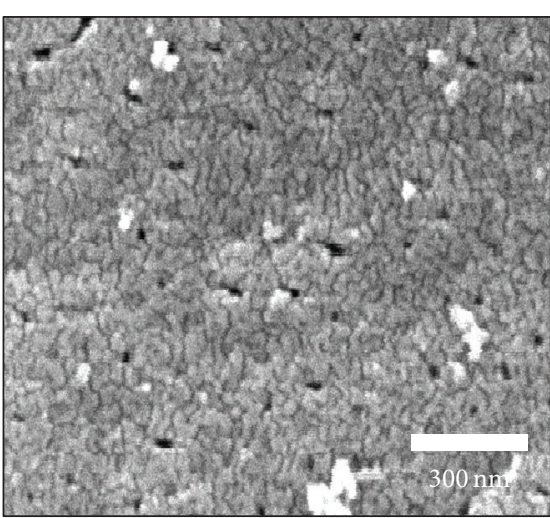

(c)

FIGURE 4: SEM images showing the morphology of the anodizing aluminum alloy specimens using sulfuric acid under (a) $40 \mathrm{~V}$, (b) $50 \mathrm{~V}$, and (c) $60 \mathrm{~V}$.

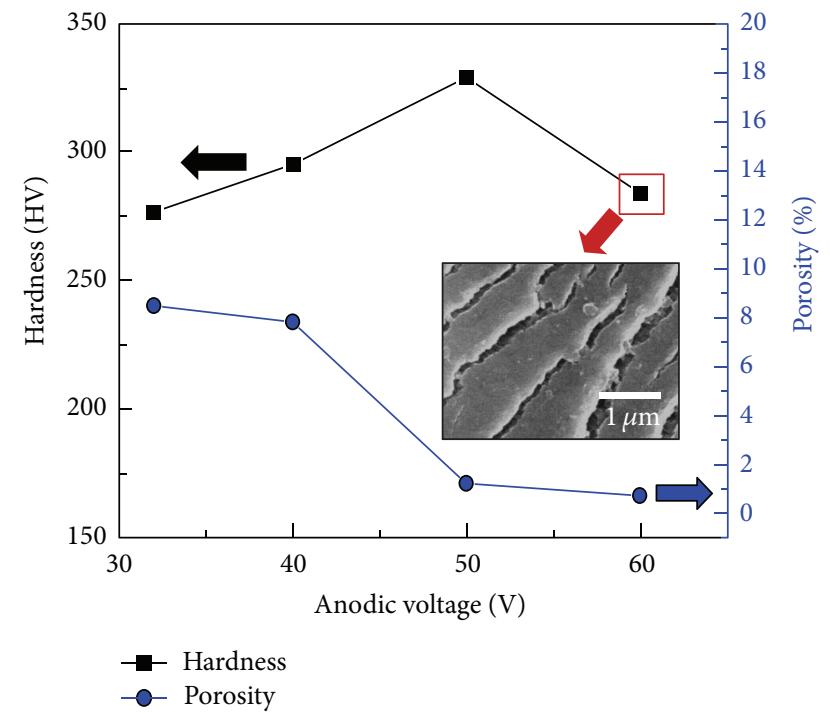

Figure 5: Oxide film hardness and porosity for the 6061-T6 aluminum alloy anodizing process under different anodic voltages using electrolytes of sulfuric acid.

the increase of oxide barrier. However, when this boundary stress reaches the critical point, the material will fail and then the stress releases so the cracks can be seen clearly in the surface of oxide films. Furthermore, current density increases with anodic voltage which reduces hardness due to the large heat production. Finally, the hardness of the oxide drops due to this weakened film structure. Moreover, as shown in Figure 3, we also found that the breakdown voltage decreases at anodic voltage $60 \mathrm{~V}$; even the thickness is still larger than $50 \mathrm{~V}$. This reason is mainly due to the surface cracks of the anodic oxide film as also shown in Figure 5. The results indicated that the electrical and mechanical properties of aluminum anodic oxide will reduce at high anodic voltage because larger oxide growth speed will induce more surface cracks of oxide films.
In summary, we have demonstrated the breakdown voltage, hardness, and mechanical behaviors of nanoporous aluminum alloy anodic oxidation by sulfuric acid anodic process. The results indicated that polish process is an important factor to stabilize the properties of anodic oxide film. Besides, the hardness and breakdown voltage will increase with increasing anodic voltage because of the increase of oxide thickness and the decrease of porosity of oxide film. However, too much applied anodic voltage will cause excessive oxide growth rate which induces the higher internal stress and causes the crack of the anodic oxide film and then it will decrease the electrical and mechanical properties of the anodic film.

\section{Conflict of Interests}

The authors declare that there is no conflict of interests regarding the publication of this paper.

\section{Acknowledgment}

The authors would like to thank the support in part by National Science Council (NSC) of Taiwan under Contract No. NSC-101-2221-E-151-010.

\section{References}

[1] T.-H. Fang, T. H. Wang, C.-H. Liu, L.-W. Ji, and S.-H. Kang, "Physical behavior of nanoporous anodic alumina using nanoindentation and microhardness tests," Nanoscale Research Letters, vol. 2, no. 8, pp. 410-415, 2007.

[2] W. S. Pinner and P. G. Sheasby, "Decorative and protective anodizing," in The Surface Treatment and Finishing of Aluminium and Its Alloys, pp. 427-596, Finishing Publications, 2001.

[3] R. H. Baughman, A. A. Zakhidov, and W. A. de Heer, "Carbon nanotubes - the route toward applications," Science, vol. 297, pp. 787-792, 2002.

[4] R. O’Barr, S. Y. Yamamoto, S. Schultz, W. Xu, and A. Scherer, "Fabrication and characterization of nanoscale arrays of nickel 
columns," Journal of Applied Physics, vol. 81, no. 8, pp. 47304732, 1997.

[5] O. Jessensky, F. Müller, and U. Gösele, "Self-organized formation of hexagonal pore arrays in anodic alumina," Applied Physics Letters, vol. 72, no. 10, pp. 1173-1175, 1998.

[6] X. Tao, Q. Shangkui, Z. Jiazheng, and C. Jianmin, "A study on the surface and interface of porous anodic oxide film of aluminium," Journal of Physics D: Applied Physics, vol. 29, no. 10, pp. 2534-2538, 1996.

[7] B. A. Scott, "Decorative and protective finishes produced on aluminum by hard anodizing," Transactions of the Institute of Metal Finishing, vol. 43, p. 1, 1965.

[8] T. Koizumi, T. Fuchigami, and T. Nonaka, "Anodic oxidation of (trimethylsily) methanes with $\pi$-electron substituents in the presence of nucleophiles," Bulletin of the Chemical Society of Japan, vol. 62, pp. 219-225, 1989.

[9] H. Masuda and K. Fukuda, "Ordered metal nanohole arrays made by a two-step replication of honeycomb structures of anodic alumina," Science, vol. 268, no. 5216, pp. 1466-1468, 1995.

[10] H. Masuda and M. Satoh, "Fabrication of gold nanodot array using anodic porous alumina as an evaporation mask," Japanese Journal of Applied Physics, vol. 35, no. 1, pp. L126-L129, 1996.

[11] H. Masuda, F. Hasegwa, and S. Ono, "Self-ordering of cell arrangement of anodic porous alumina formed in sulfuric acid solution," Journal of the Electrochemical Society, vol. 144, no. 5, pp. L127-L130, 1997.

[12] J. P. O'Sullivan and G. C. Wood, "Morphology and mechanism of formation of porous anodic films on aluminum," Proceedings of the Royal Society of London, Series A: Mathematical and Physical Sciences, vol. 317, no. 1531, pp. 511-543, 1970.

[13] X. Tao, Q. Shangkui, Z. Jiazheng, and C. Jianmin, "A study on the surface and interface of porous anodic oxide film of aluminium," Journal of Physics D: Applied Physics, vol. 29, no. 10, article 2534, 1996.

[14] F. Keller, M. S. Hunter, and D. L. Robinson, "Structural features of oxide coatings on aluminum," Journal of the Electrochemical Society, vol. 100, no. 9, pp. 411-419, 1953.

[15] V. Surganov, "Planarized thin film inductors and capacitors for hybrid integrated circuits made of aluminum and anodic alumina," IEEE Transactions on Components, Packaging and Manufacturing Technology. Part B. Advanced Packaging, vol. 17, pp. 197-200, 1994.

[16] V. Surganov and A. Mozalev, "Planar aluminum interconnection formed by electrochemical anodizing technique," Microelectronic Engineering, vol. 37-38, pp. 329-334, 1997.

[17] T. W. Hickmott, "Voltage-dependent dielectric breakdown and voltage controlled negative resistance in anodized $\mathrm{Al}_{-} \mathrm{Al}_{2} \mathrm{O}_{3}-\mathrm{Au}$ diodes," Journal of Applied Physics, vol. 88, no. 5, pp. 2805-2812, 2000.

[18] T. W. Hickmott, "Interface states at the anodized $\mathrm{Al}_{2} \mathrm{O}_{3}$-metal interface," Journal of Applied Physics, vol. 89, no. 10, pp. 55025508, 2001.

[19] G. E. Thompson, Y. Xu, P. Skeldon, K. Shimizu, S. H. Han, and G. C. Wood, "Anodic oxidation of aluminium," Philosophical Magazine B, vol. 55, no. 6, pp. 651-667, 1987.

[20] X. Zhou, G. E. Thompson, P. Skeldon, G. C. Wood, K. Shimizu, and H. Habazaki, "Film formation and detachment during anodizing of Al-Mg alloys," Corrosion Science, vol. 41, no. 8, pp. 1599-1613, 1999.
[21] K. Shimizu, K. Kobayashi, G. E. Thompson, and G. C. Wood, "A novel marker for the determination of transport numbers during anodic barrier oxide growth on aluminium," Philosophical Magazine B, vol. 64, no. 3, pp. 345-353, 1991.

[22] G. E. Thompson, "Porous anodic alumina: fabrication, characterization and applications," Thin Solid Films, vol. 297, no. 1-2, pp. 192-201, 1997.

[23] A. R. Despić, "A note on the effect of the electrolyte on the type of growth of anodic oxide on aluminium," Journal of Electroanalytical Chemistry and Interfacial Electrochemistry, vol. 191, no. 2, pp. 417-423, 1985.

[24] S.-Z. Chu, K. Wada, S. Inoue, M. Isogai, and A. Yasumori, "Fabrication of ideally ordered nanoporous alumina films and integrated alumina nanotubule arrays by high-field anodization," Advanced Materials, vol. 17, no. 17, pp. 2115-2119, 2005.

[25] Y. Li, M. J. Zheng, L. Ma, and W. Shen, "Fabrication of highly ordered nanoporous alumina films by stable high-field anodization," Nanotechnology, vol. 17, no. 20, pp. 5101-5105, 2006.

[26] H. Masuda and M. Satoh, "Fabrication of gold nanodot array using anodic porous alumina as an evaporation mask," Japanese Journal of Applied Physics Part 2, vol. 35, no. 1, pp. L126-L129, 1996. 

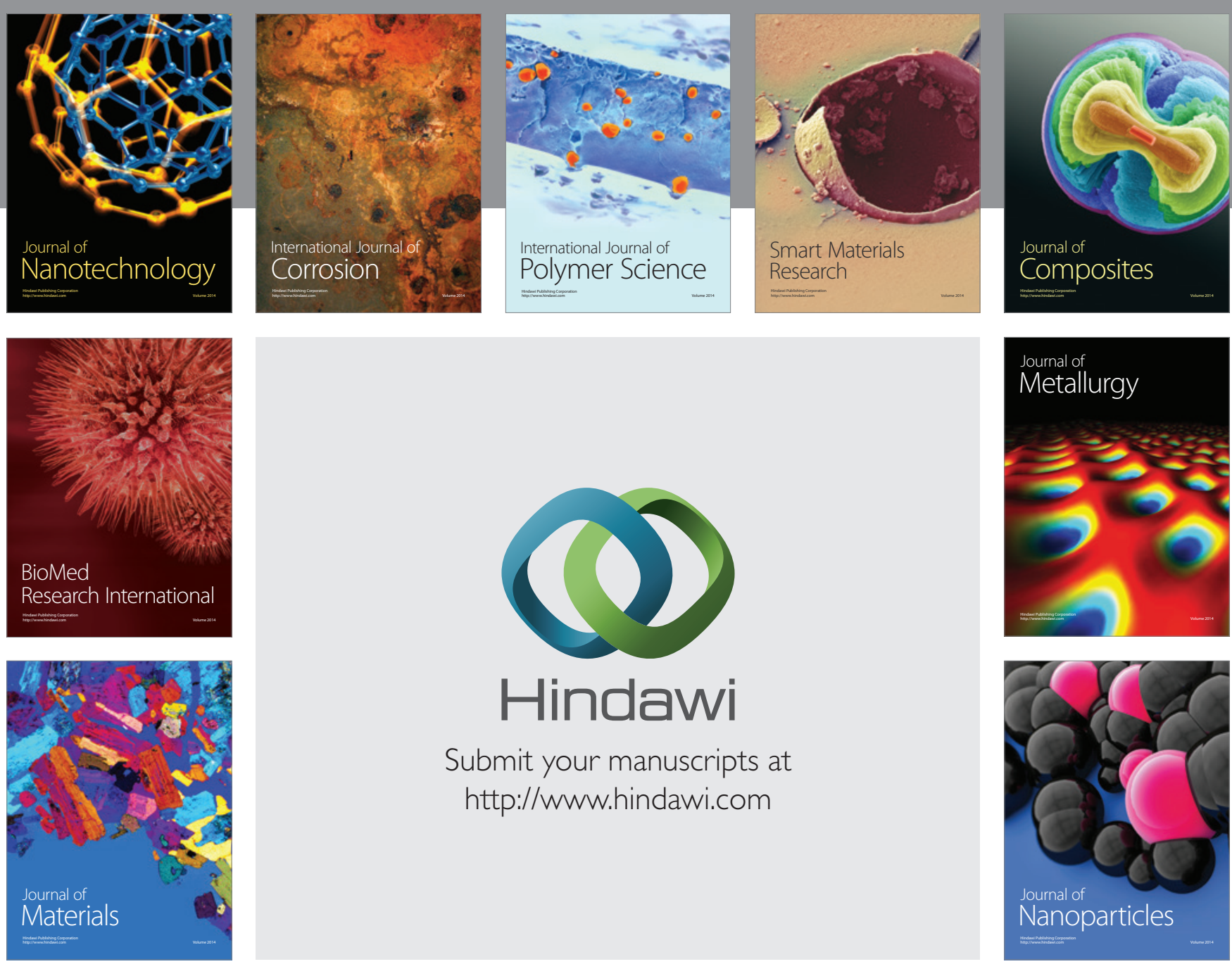

Submit your manuscripts at http://www.hindawi.com
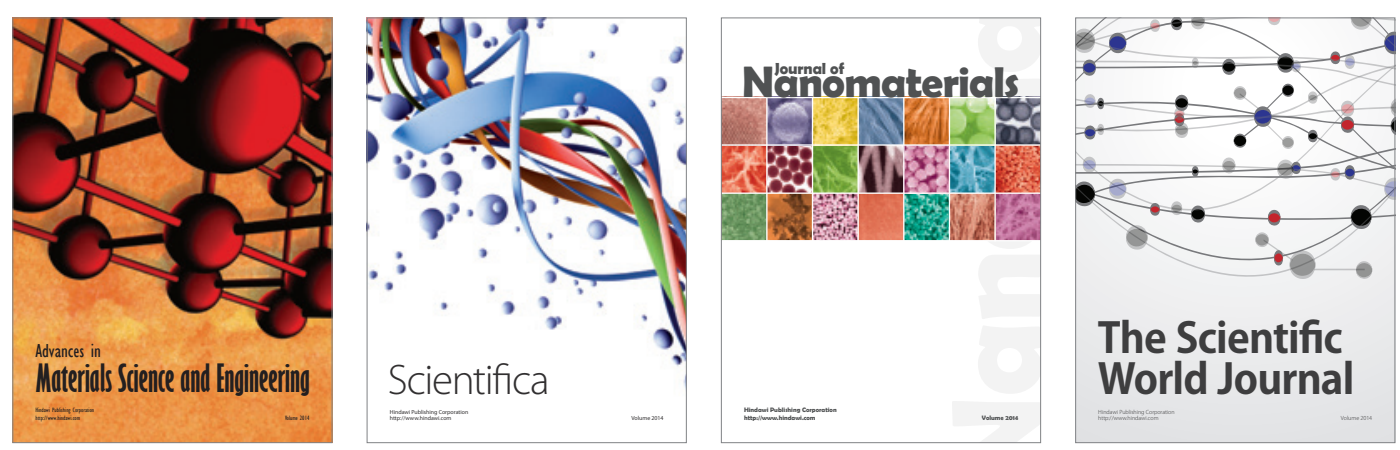

\section{The Scientific World Journal}
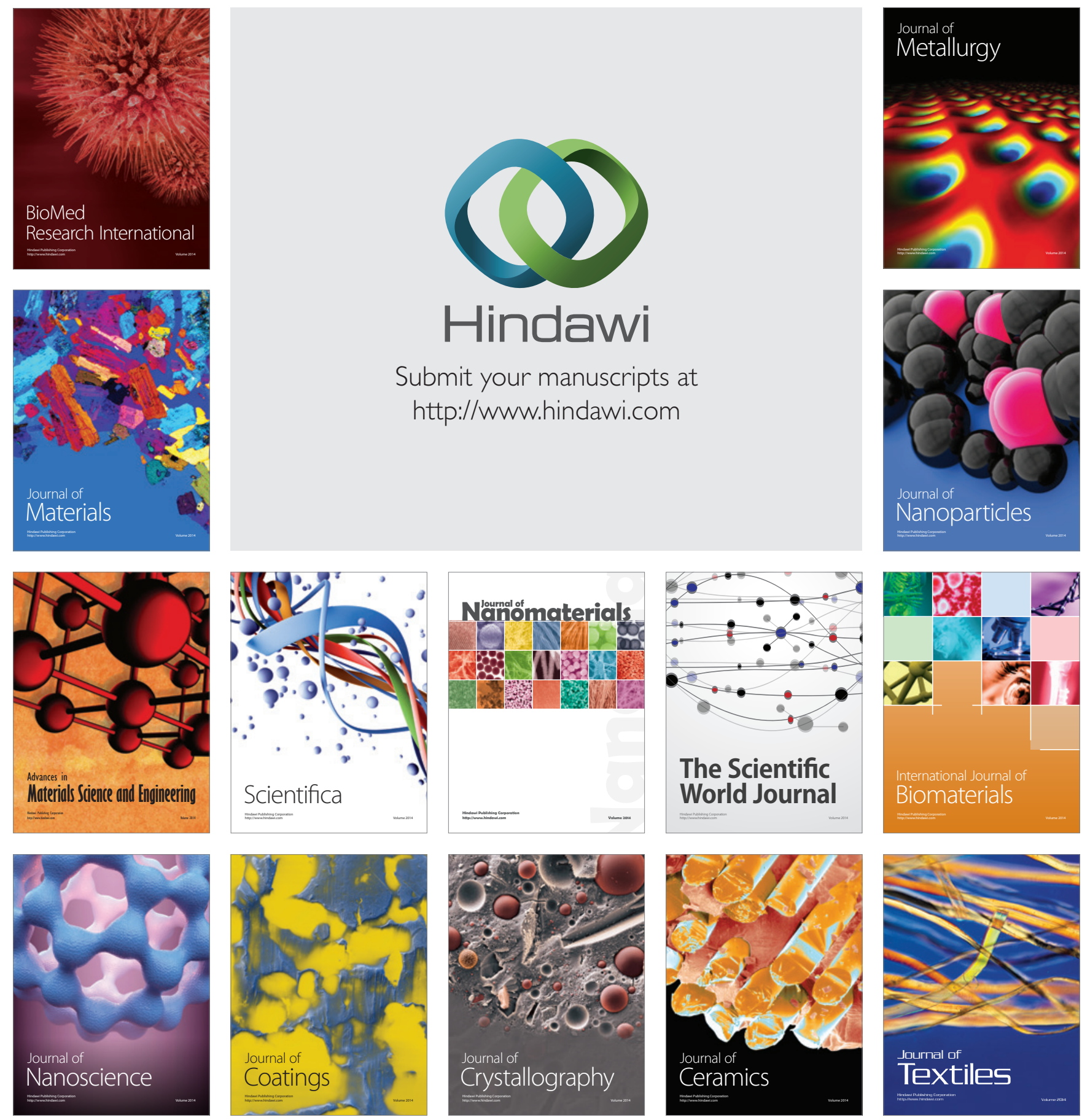